\title{
Intraamniotic Route of Administration
}

National Cancer Institute

\section{Source}

National Cancer Institute. Intraamniotic Route of Administration. NCI Thesaurus. Code C38221.

Administration of the drug within the amnion. 